\title{
Encapsulation of clove oil in nanostructured lipid carriers from natural waxes: Preparation, characterization and in vitro evaluation of the cholinesterase enzymes
}

\author{
Alessandra Cristina de Meneses ${ }^{\mathrm{a}}$, Elisa Balbi Pinto Marques ${ }^{\mathrm{a}}$, Fernanda Vitória Leimann ${ }^{\mathrm{b}, \mathrm{c}, \mathrm{d}}$, \\ Odinei Hess Gonçalves ${ }^{\mathrm{b}, \mathrm{c}, \mathrm{d}}$, Rafael Porto Ineu ${ }^{\mathrm{b}}$, Pedro Henrique Hermes de Araújo ${ }^{\mathrm{a}}$, \\ Débora de Oliveira ${ }^{\mathrm{a}}$, Claudia Sayer ${ }^{\mathrm{a} \text {,* }}$ \\ ${ }^{a}$ Departamento de Engenharia Química e Engenharia de Alimentos (EQA), Universidade Federal de Santa Catarina (UFSC), Florianópolis, SC, Brazil \\ b Programa de Pós-Graduação em Tecnologia de Alimentos, Universidade Tecnológica Federal do Paraná (UTFPR), Campo Mourão, PR, Brazil \\ ${ }^{\mathrm{c}}$ Centro de Investigação de Montanha (CIMO), Instituto Politécnico de Bragança, Campus de Santa Apolónia, 5300-253, Bragança, Portugal \\ ${ }^{\mathrm{d}}$ Laboratory of Separation and Reaction Engineering - Laboratory of Catalysis and Materials (LSRE-LCM), Polytechnic Institute of Bragança, Campus Santa Apolónia, \\ 5301-253, Bragança, Portugal
}

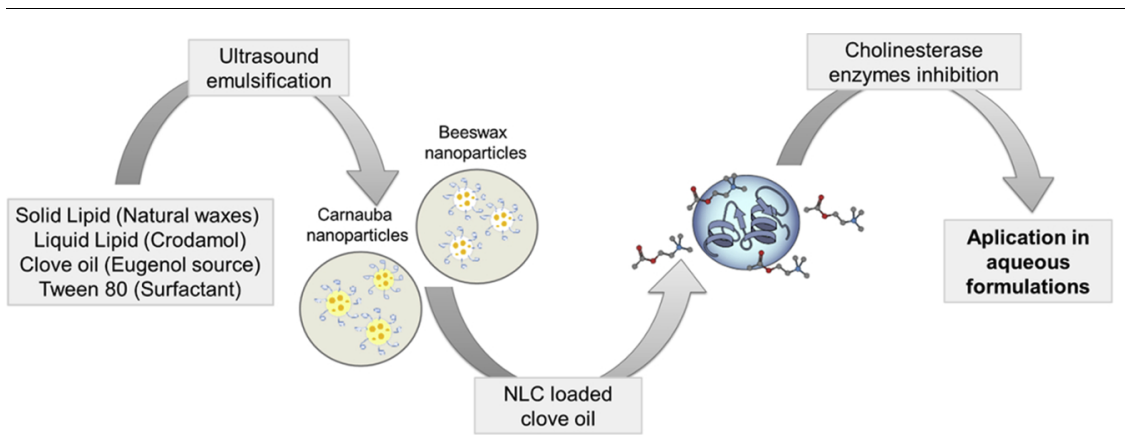

\section{A R T I C L E I N F O}

\section{Keywords:}

Encapsulation

Clove oil

Carnauba wax

Beeswax

Drosophila melanogaster

Butyrylcholinesterase

Acetylcholinesterase

\begin{abstract}
A B S T R A C T
Eugenol is a phenolic compound largely found in the clove essential oil that possesses promising biological activity. However, its low water solubility is a major concern and encapsulation is an alternative to improve water affinity. The objective of this work was to produce nanostructured lipid carriers (NLC) by hot homogenization/ultrasound emulsification and to evaluate the effect of free and encapsulated clove oil on the in vitro cholinesterase enzymes modulation using Drosophila melanogaster (DM) tissue. The NLC composed of a natural wax (carnauba or beeswax) and crodamol showed an average diameter between 121 and $367 \mathrm{~nm}$ with good dispersion and colloidal stability. The spherical shape and solid character together with the semi-crystalline environment confirm the formation of NLC. DSC analysis indicated polymorphic transition events of the waxes. In vitro tests using DM demonstrated that
\end{abstract}

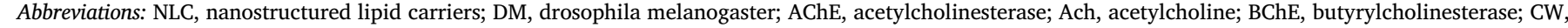

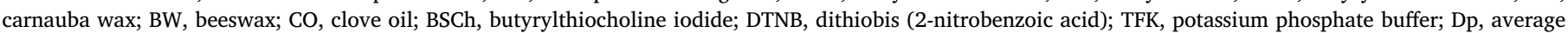

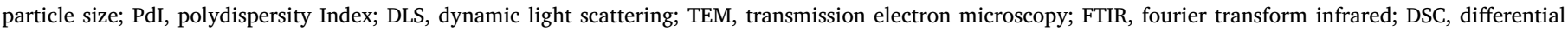

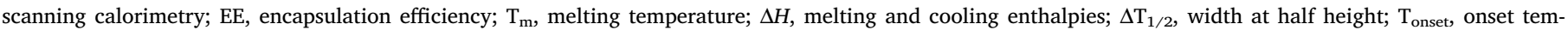
peratures

* Corresponding author at: Universidade Federal de Santa Catarina (UFSC), Departamento Engenharia Química e Engenharia de Alimentos (EQA), Laboratório de Controle de Processos, Campus Trindade, Cx. Postal 476, 88010-970, Florianópolis, SC, Brazil.

E-mail address: claudia.sayer@ufsc.br (C. Sayer).
} 
free clove oil showed a good inhibition of the butyryl and acetylcholinesterase enzymes above a concentration of $10 \mathrm{mM}$, with $\mathrm{IC}_{50}$ values of 4.3 and $3.5 \mathrm{mM}$, respectively. The dispersions of the NLC loaded with clove oil showed a decrease in the $\mathrm{IC}_{50}$ enzymes values, indicating the preservation of the clove essential oil and suggesting an increased in the solubility. Results indicate that NLC dispersions have good potential to be used for foods and cosmetic aqueous formulations possessing biological activity.

\section{Introduction}

Phenolic compounds are found naturally in many fruits, vegetables, and nuts, as secondary metabolites. Chemically, these compounds have one or more hydroxyl group attached to a benzene ring and play an important role in the human diet by exerting various biological effects such as free radical scavenging, metal chelation, modulation of enzymatic activity and altering signal transduction pathways [1-3]. Eugenol is the major component of clove oil, approximately $90-95 \%$, responsible for the specific clove aroma and known as a good agent for human health due to the biological activities and also for the specific clove oil aroma [3-12].

The antioxidant potential of eugenol was extensively studied in the literature [6,10,13-17], and some studies associating this antioxidant property with acetylcholinesterase inhibition were also reported $[3,7]$. The acetylcholinesterase (AChE - EC 3.1.1.7) is an enzyme responsible for the termination of cholinergic signaling by hydrolyzing acetylcholine (ACh) and the inhibition of AChE is effective in the treatment and management of Alzheimer's disease, multiple system atrophy, and other conditions $[3,7,18]$. Acetylcholine hydrolysis can also be catalyzed by butyrylcholinesterase (BChE - EC 3.1.1.8, also known as serum cholinesterase or pseudo-cholinesterase), a related and less-specific enzyme [18], however, to the best of the authors knowledge there is no report in literature about eugenol as a potential modulator of BChE activity.

Although some research groups have been investigating eugenol as potential AChE inhibitor [19-22] all studies involve the use of the clove oil in the free form, and the concentration needed to ensure an effective activity as AChE inhibitor may be difficult to reach in actual biological systems due to the hydrophobic character of the essential oil. In addition, eugenol is volatile and chemically unstable in the presence of air and light, and its encapsulation may be a positive alternative since the main objective is to protect the bioactive compound against the adverse environmental conditions. In this way, the incorporation of the essential oil in a lipid matrix may improve the solubility and the bioavailability in the medium. The lipid nanoparticles are generally made by biodegradable lipids that can be solid at room and body temperature and possess several advantages like high drug loading, increased drug stability, controlled drug release, and enhanced penetration of drugs into the skin or any other target [23-25]. The nanostructured lipid carriers (NLC) loaded with essential oils can be easily incorporated in water-rich cosmetic and food formulations, expanding its range of application and improving bioactive compound shelf life as already reported by other works [26-28].

In the present work clove oil, a great source of eugenol, was incorporated in NLC made from either carnauba wax (CW) or beeswax (BW) using the hot homogenization/ultrasound emulsification technique. The waxes obtained from natural sources like carnauba and bees are composed of hydrocarbons, alcohols, free acids, esters, and other materials, which have many advantages due to the low toxicity and biocompatibility making the final product interesting for several applications [29]. The obtained aqueous NLC dispersions were evaluated in relation to particle diameter, distribution, and morphology, clove oil encapsulation efficiency, as well as by chemical and thermal analyses. In addition, $\mathrm{AChE}$ and $\mathrm{BChE}$ activities were verified in vitro for the free and encapsulated clove oil using a Drosophila melanogaster (DM) tissue as biological model. DM is widely used in biological tests due to the great similarity with the human genetic sequence, allowing the understanding of complex biological problems $[30,31]$ and it was used in the present study as an alternative biological model to test the NLC loaded clove oil effects in the cholinergic enzymes AChE and BChE.

\section{Experimental}

\subsection{Materials}

NLC production involved the use of carnauba wax (CW) and beeswax (BW) as solid lipids kindly donated by GM Ceras Ltda/ Brazil, crodamol GTCC (saturated triglyceride from coconut oil, Alpha Química, Brazil) as liquid lipid, clove oil (CO - 92\% Eugenol) from Ferquima/Brazil as bioactive compound, polysorbate 80 (Tween 80 Sigma-Aldrich) as surfactant, and distilled water as aqueous phase. It is worth noting that Tween 80 and crodamol are considered safe food ingredients by FDA and were used in NLC formulations [32]. For AChE and $\mathrm{BChE}$ activities tests were used acetylthiocholine iodine (ASCh), butyrylthiocholine iodide (BSCh),5,5'-Dithiobis(2-nitrobenzoic acid) (DTNB, 98\% purchased from Sigma-Aldrich/Brazil) and methanol (P.A., NEON). Mono and dibasic potassium phosphate (NEON) were used to prepare TFK buffer and tris-(hydroxymethyl)aminomethane

Table 1

Composition of the organic phase of carnauba wax (CW) and beeswax (BW) NLC, average particle diameter (Dp), polydispersity index (PdI), and encapsulation efficiency (EE) of the nanoparticles at day 1,15 and 30 .

\begin{tabular}{|c|c|c|c|c|c|c|c|c|c|}
\hline \multirow[t]{2}{*}{ Sample } & \multirow[t]{2}{*}{ Wax $(g)$} & \multirow[t]{2}{*}{ Crod (g) } & \multirow[t]{2}{*}{$\mathrm{CO}(\mathrm{g})$} & \multicolumn{3}{|c|}{$\mathrm{Dp}(\mathrm{nm}) / \mathrm{PdI}$} & \multicolumn{3}{|l|}{ EE (\%) } \\
\hline & & & & Day 1 & Day 15 & Day 30 & Day 1 & Day 15 & Day 30 \\
\hline CW1 & 3 & - & - & $1489 / 0.27$ & - & - & - & - & - \\
\hline CW2 & 2 & - & - & $613 / 0.31$ & - & - & - & - & - \\
\hline CW3 & 1 & - & - & $178 / 0.27$ & $301 / 0.43$ & $381 / 0.52$ & - & - & - \\
\hline CW4 & 0.9 & 0.1 & - & $121 / 0.08$ & $122 / 0.09$ & $125 / 0.12$ & - & - & - \\
\hline CW5 & 0.9 & 0.075 & 0.025 & $126 / 0.11$ & $128 / 0.11$ & $130 / 0.10$ & $58 \pm 0$ & $58 \pm 0$ & $56 \pm 1$ \\
\hline CW6 & 0.9 & 0.05 & 0.05 & $150 / 0.19$ & $146 / 0.18$ & $152 / 0.16$ & $60 \pm 2$ & $61 \pm 3$ & $58 \pm 1$ \\
\hline BW1 & 3 & - & - & $443 / 0.165$ & - & - & - & - & - \\
\hline BW2 & 2 & - & - & $320 / 0.12$ & - & - & - & - & - \\
\hline BW3 & 1 & - & - & $324 / 0.15$ & $617 / 0.58$ & $698 / 0.64$ & & - & - \\
\hline BW4 & 1.8 & 0.2 & - & $227 / 0.09$ & $229 / 0.09$ & $231 / 0.12$ & - & - & - \\
\hline BW5 & 1.8 & 0.1 & 0.1 & $272 / 0.09$ & $242 / 0.09$ & $260 / 0.13$ & $66 \pm 1$ & $66 \pm 0$ & $64 \pm 0$ \\
\hline BW6 & 1.8 & 0.05 & 0.15 & $342 / 0.08$ & $349 / 0.06$ & $357 / 0.10$ & $64 \pm 1$ & $65 \pm 0$ & $63 \pm 2$ \\
\hline BW7 & 1.8 & 0.02 & 0.18 & $368 / 0.10$ & $394 / 0.12$ & $401 / 0.14$ & $63 \pm 0$ & $63 \pm 0$ & $60 \pm 2$ \\
\hline
\end{tabular}


(Tris) from Sigma-Aldrich. All other chemicals were analytical grade and purchased from local sources. Drosophila melanogaster (DM) wild type flies were obtained from the National Species Stock Center (Bowling Green, OH, USA) and were used as source of biological tissue.

\subsection{Preparation of the wax nanoparticles by ultrasound emulsification}

The NLC production was conducted by the hot homogenization/ultrasound emulsification technique described elsewhere with some modifications [33]. Initially, the lipid and aqueous phases were prepared separately. The aqueous phase was prepared dissolving 3\%wt of Tween 80 in water $(10 \mathrm{~mL})$. The lipid phase was composed of different amounts of CW or BW, crodamol and clove oil as shown in Table 1 . In sequence, the physical mixture of the organic components was made under heat $\left(10^{\circ} \mathrm{C}\right.$ above the melting point of the wax) and after complete melting, the aqueous phase (previously heated to the same temperature) was added to the organic phase. Both phases were intensely homogenized for $15 \mathrm{~min}$ in a hot bath with orbital agitation to form a coarse emulsion. Then, the emulsion was submitted to high-energy emulsification by an Ultrasonic Dismembrator (Fischer Scientific 500, $400 \mathrm{~W}$ ) at $50 \%$ of amplitude in pulsed regime for $1 \mathrm{~min}$ ( $30 \mathrm{~s}$ on $10 \mathrm{~s}$ off) in order to reduce the melted droplets to the nanometric range. Finally, the melted wax nanodroplets were cooled in cold water $\left(90 \mathrm{~mL}\right.$ at $\left.4^{\circ} \mathrm{C}\right)$ to form solid nanoparticles (final volume $100 \mathrm{~mL}$ ).

\subsection{Particles characterization}

Intensity average particle size (Dp) and polydispersity index (PdI) of the NLC were determined by Dynamic Light Scattering (DLS) using a Zeta Sizer Nano S (Malvern Instruments). The formulations were analyzed right after the production (Day 1 ) and after 15 and 30 days of storage at room temperature (Day 15 and 30). For that, the samples were properly diluted in water and measured at $25{ }^{\circ} \mathrm{C}$ in a glass cuvette. Transmission Electron Microscopy (TEM $100 \mathrm{kV} \mathrm{JEM-101)} \mathrm{was} \mathrm{carried} \mathrm{out} \mathrm{to} \mathrm{in-}$ vestigate the particle morphology of the CW and BW NLC. For that, each sample was diluted in distilled water up to $0.1 \% \mathrm{wt}$ solids, and then, one drop of each diluted sample was placed on a carbon-coated 400 mesh copper grid of and dried overnight under room conditions. The chemical analysis was performed by Fourier Transform Infrared (FTIR) spectroscopy using a Shimadzu IRPrestige-21. The pure clove oil, bulk waxes, and lyophilized NLC samples were analyzed using the potassium bromide ( $\mathrm{KBr}$ ) pellet method. Spectra were taken in the range of 4000 to 400 $\mathrm{cm}^{-1}$ with 32 cumulative scans. Lyophilized NLC samples and bulk waxes were analyzed by Differential Scanning Calorimetry (DSC 4000 Perkin Elmer) under inert atmosphere $\left(\mathrm{N}_{2}, 20 \mathrm{~mL} \cdot \mathrm{min}^{-1}\right)$, from 0 to $100^{\circ} \mathrm{C}$ at a heating rate of $10^{\circ} \mathrm{C}$. $\mathrm{min}^{-1}$. The thermal history was removed under a heating rate of $20^{\circ} \mathrm{C} . \mathrm{min}^{-1}$ and cooling rate of $-20^{\circ} \mathrm{C}$. $\mathrm{min}^{-1}$. DSC heating and cooling curves were obtained from the second and first run, respectively. Calorimetric parameters including the melting temperatures $\left(\mathrm{T}_{\mathrm{m}}\right)$, melting and cooling enthalpies enthalpy $(\Delta H)$, width at half height $\left(\Delta \mathrm{T}_{1 / 2}\right)$ and onset temperatures $\left(\mathrm{T}_{\text {onset }}\right)$ were analyzed using the Pyris Manager software (PerkinElmer). The crystallinity index (CI) of NLC formulations were calculated using Eq. (1):

$C I=\frac{\Delta H_{m N L C}}{\Delta H_{\operatorname{mwax}}} \times 100 \%$

where, $\Delta H_{m N L C}$ and $\Delta H_{\text {mwax }}$ are the melting enthalpy of the NLC sample and pure wax, respectively [29,34].

The clove oil encapsulation efficiency (EE) in the NLC matrix was determined by the analysis of the free clove oil in the aqueous phase of the NLC dispersion. The NLC dispersions containing clove oil $(500 \mu \mathrm{L})$ were ultra-filtrated using an Eppendorf with an Amicon Ultra 0.5 coupled to a filter (Millipore ${ }^{\circledast}, 100 \mathrm{kDa}$ ) at $10,000 \mathrm{rpm}$ for $10 \mathrm{~min}$. An aliquot of the filtered liquid was adequately diluted in ethanol, transferred to a quartz cuvette and analyzed in the wavelength of $280 \mathrm{~nm}$ in a UV-vis spectrophotometer (Hitachi U-1900). The concentration of free clove oil was calculated as previously described elsewhere [35].

\subsection{Tissue preparation}

The Drosophila Melanogaster homogenate was prepared as described elsewhere with minor modifications [31]. Adults flies (both gender) were maintained and cultured in cornmeal medium $(2 \% \mathrm{w} / \mathrm{v}$ sucrose, $1.6 \% \mathrm{w} / \mathrm{v}$ powdered milk, $0.2 \%$ salt, and $0.05 \% \mathrm{w} / \mathrm{v}$ methylparaben) during $12 \mathrm{~h}$ dark/light cycle conditions at constant temperature $\left(22-24^{\circ} \mathrm{C}\right)$ and humidity $(45-65 \%)$. One hundred adult flies were cold anesthetized in a domestic freezer and manually homogenized in $1 \mathrm{~mL}$ of Tris $-\mathrm{HCl}$ solution ( $50 \mathrm{mM}, \mathrm{pH} 7)$. In sequence, samples were centrifuged at $12,000 \mathrm{rpm}$ for $10 \mathrm{~min}$ and the supernatant (S1) was used as DM homogenate in the in vitro AChE and BChE tests.

\subsection{In vitro cholinergic activity}

Acetylcholinesterase (AChE) and butyrylcholinesterase (BChE) activity were measured by the assay described by Ellman et al. [36] considering some modifications described by Hammond and Forster [37] and Dohi et al. [7] using DM homogenate as enzymes source. The $\mathrm{IC}_{50}$ was determined plotting the graphs and line equations between the clove oil concentration versus the $I \%$ to each system.

Free clove oil: Initially, solutions with appropriate clove oil concentrations were prepared by sequential dilution of the essential oil in methanol. In sequence, TFK $(25 \mu \mathrm{L}, 100 \mathrm{mM})$ and $\mathrm{S} 1(12.5 \mu \mathrm{L})$ were placed in a 96-well microplate and dissolved with $12.5 \mu \mathrm{L}$ of each previously prepared clove oil methanolic solution. At this point, the time zero (abs $t_{0}$ ) reading was performed in a microplate reader (Thermo-Plate Reader) at $405 \mathrm{~nm}$. After a pre-incubation at $37 \pm 1{ }^{\circ} \mathrm{C}$ for $15 \mathrm{~min}$, DTNB $(62.5 \mu \mathrm{L}, 2 \mathrm{mM})$ and substrate $(12.5 \mu \mathrm{L}$, ASCh or BSCh $8 \mathrm{mM}$ ) were added into the wells and then incubated at room temperature for $15 \mathrm{~min}$. The absorbance of the final mixtures was measured at the end of the incubation time (abs $t_{\text {final }}$ ). A control mixture was prepared by using $12.5 \mu \mathrm{L}$ of pure methanol instead of the methanolic oil sample. The inhibition percentage was determined by Eq. (2).

$I(\%)=100-\frac{A b s_{\text {sample }}}{A b s_{\text {control }}} \times 100$

where, $A b s_{\text {sample }}$ is the absorbance of the sample containing clove oil and $A b s_{\text {control }}$ is the absorbance of the control without the essential oil.

Clove oil-loaded NLC: Initially, appropriated NLC concentrations were prepared by sequential dilutions of the NLC aqueous dispersion in water. In sequence, $12.5 \mu \mathrm{L}$ of TFK ( $100 \mathrm{mM}), 12.5 \mu \mathrm{L}$ of methanol, and $12.5 \mu \mathrm{L}$ of DM homogenate were placed in a 96-well microplate and mixed with $12.5 \mu \mathrm{L}$ of each previously prepared NLC dispersion. All the other procedures including incubation time and temperature, absorbance reading, the addition of DTNB and substrates, and percentage of inhibition (I\%) were the same as those described for "Free clove oil as inhibitor". Otherwise, the control mixture was prepared using NLC dispersion with no clove oil (blank sample) but with the same solids content.

\subsection{Statistical analyses}

Biological results are presented as mean \pm standard deviation. Oneway ANOVA was used to investigate the significant difference in the in vitro experiments following by Tukey post hoc test with $5 \%$ significance level. Analyses were conducted on GraphPad Prism 5 software.

\section{Results and discussion}

\subsection{Particles characterization}

The NLC were produced using BW or CW and crodamol as matrix material, and different formulations were tested with varying amounts of wax as solid lipid, crodamol as liquid lipid, and clove oil as bioactive compound. The formulations and Dp, PdI and EE results are presented 
in Table 1. Transmission Electron Microscopy images of selected samples are showed in Fig.1.

The use of carnauba wax as matrix material systematically resulted in particles with higher Dp and PdI when compared to beeswax. However, in all cases, Dp values between 120 and $1489 \mathrm{~nm}$ with narrow distributions were found, which may be interesting depending on the desired application. The carnauba wax formulations containing a single lipid in organic phase (CW1, CW2, and CW3) showed a pronounced increase of the Dp with increasing wax amount used, as compared to the BW formulations, which may be associated to the CW higher chain length, and consequently, higher viscosity [38]. The use of $10 \mathrm{wt} \%$ (related to the organic phase, CW4 and BW4) of crodamol as liquid lipid favored a noteworthy reduction in Dp as well as in the PdI for formulations with either CW or BW. A similar effect was observed in other studies [33,34] which related the reduction of the Dp to the decrease in the organic phase viscosity, decreasing the resistance of the melted droplets disruption during emulsification/sonication.

After the incorporation of the clove oil in the formulations, a slight increase in Dp was visualized for all preparations, probably due to the reduction of the crodamol percentage in the organic phase, but it was still ensured a monomodal and homogeneous dispersion with PdI below 0.2.

The presence of the liquid lipid played an important role in the particle stability of the formulations. The absence of crodamol in the formulation resulted in a great increase in Dp and PdI after storage, while the formulations containing $10 \mathrm{wt} \%$ of crodamol (related to the organic phase) showed just a slight increase in Dp and distributions for both waxes, still showing a good colloidal stability. Results indicate that the SLN formulations containing only wax were more susceptible to aggregation with an increase on the Dp and PdI. On the other hand, the binary lipid NLC formulations showed a slight change in Dp and PdI after storage, indicating more stable structure, consequently, a lower disposition to aggregation.

TEM images confirmed the nanometric range of the lipid particles with diameters compatible with those measured by DLS. The spherical shape (almost oval for the BW NLC), smooth surface, and solid character indicate that no core-shell morphology was formed, but rather a solid particle with the crodamol and the bioactive compound distributed uniformly in the lipid sphere. This solid/no core morphology is usually expected for the NLC formulations composed of the mixture of solid and liquid lipids. Although the use of a liquid lipid is essential for drug accommodation it just ensures distances between the long fatty acids chains from waxes forming imperfections in the crystal, allowing room to active compound loading but not room enough to form a core even at high liquid lipid amounts [32,39].

All formulations showed a good capacity to incorporate different amounts of clove oil with EE around $60 \%$, and beeswax formulations (higher amount of dispersed phase) were able to incorporate higher amounts of clove oil than the carnauba wax formulations. In addition, even after 30 days of storage, no decrease was observed in the EE showing that the bioactive compound had a good affinity for the NLC matrix.

Free clove oil, bulk CW and BW, and NLC formulations (without and with the highest amount of clove oil) were analyzed by FTIR and the spectra are shown in Fig.2.

Spectrum a shows typical eugenol peaks, including a large band related to the hydroxyl group $(\mathrm{O}-\mathrm{H})$ stretch around 3550 and $3200 \mathrm{~cm}^{-1}$, peaks at 2950 and $2980 \mathrm{~cm}^{-1}$ related to axial deformation of the groups $\mathrm{CH}_{2}$ and $\mathrm{CH}_{3}$. The peak at $1640 \mathrm{~cm}^{-1}$ is related to weak axial deformation of the alkene group $\mathrm{C}=\mathrm{C}, 1540 \mathrm{~cm}^{-1}$ to the axial deformation of $\mathrm{C}=\mathrm{C}$ of the benzene ring, at $1033 \mathrm{~cm}^{-1}$ a peak related to aromatic $\mathrm{C}-\mathrm{H}$ is observed and at $750 \mathrm{~cm}^{-1}$ out-of-plane angular deformation related to $\mathrm{C}-\mathrm{H}$ of the aromatic ring [40,41].

Spectra $\mathbf{b}$ and $\mathbf{c}$ show the peaks referent to carnauba wax and beeswax. The regions 2925 and $2850 \mathrm{~cm}^{-1}$ are related to the symmetric and asymmetric vibrations of the $\mathrm{CH}_{3}$ group and the peak at $714 \mathrm{~cm}^{-1}$ confirms the asymmetric angular deformation of the long hydrocarbon chains $\mathrm{CH}_{2}$. Still, the peaks in the region of 1739 and $1103 \mathrm{~cm}^{-1}$ indicate, respectively, the stretch of $\mathrm{C}=\mathrm{O}$ from the o carboxyl groups and $\mathrm{C}-\mathrm{O}$ stretch from the ester group $[42,43]$. Although in lower intensity, the same peaks were found in the NLC spectra (d, e, f, $\mathbf{g}$ ), indicating that the matrix material maintained the original characteristics after the NLC production. On the other hand, no eugenol characteristic peak
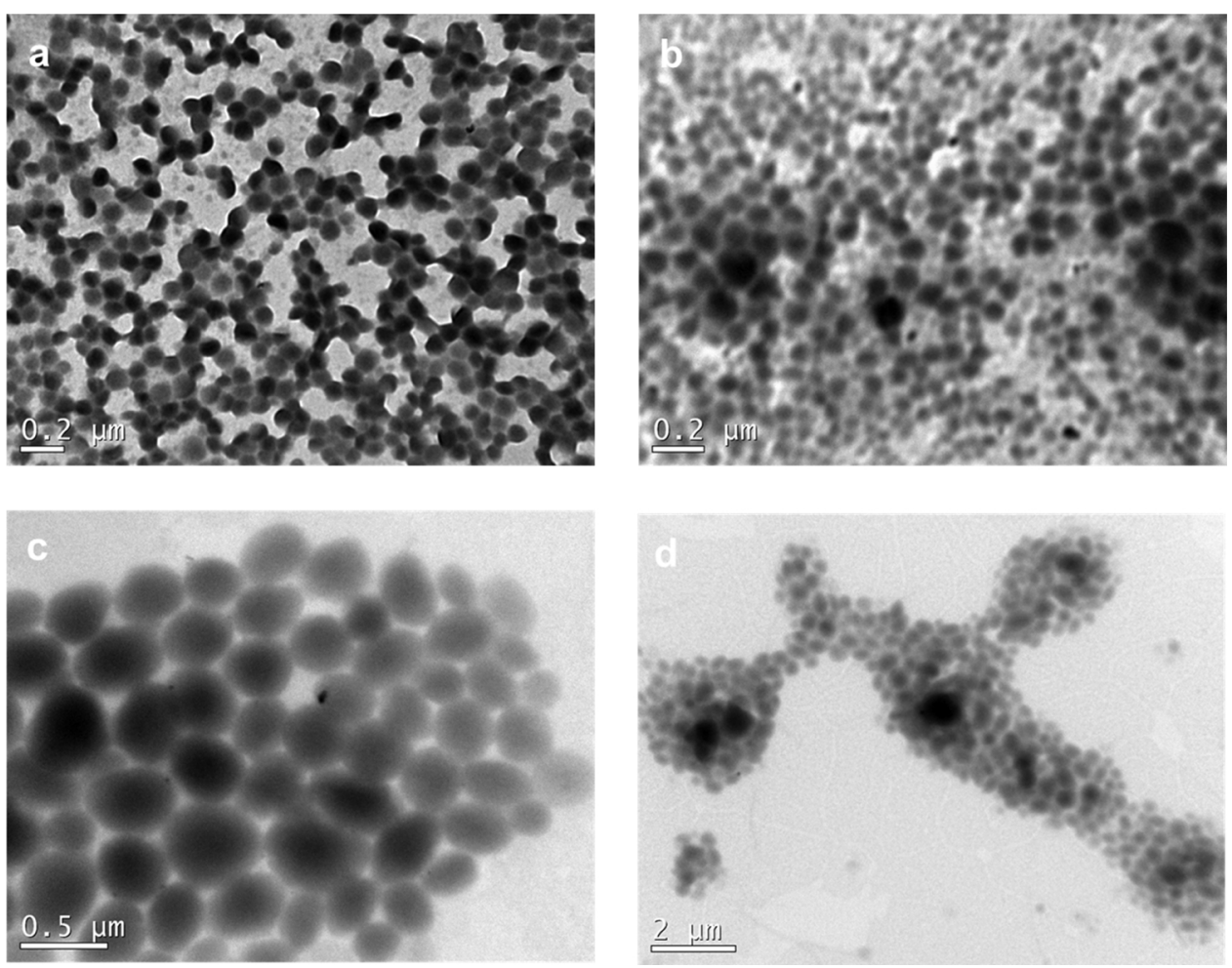

Fig. 1. TEM micrographs of the NLC formulations (a) CW4, (b) CW6, (c) BW4 and (d) BW7. The scale bar of the figures a, b, c and d corresponding, respectively, to $0.2,0.2,0.5$ and $2 \mu \mathrm{m}$. 


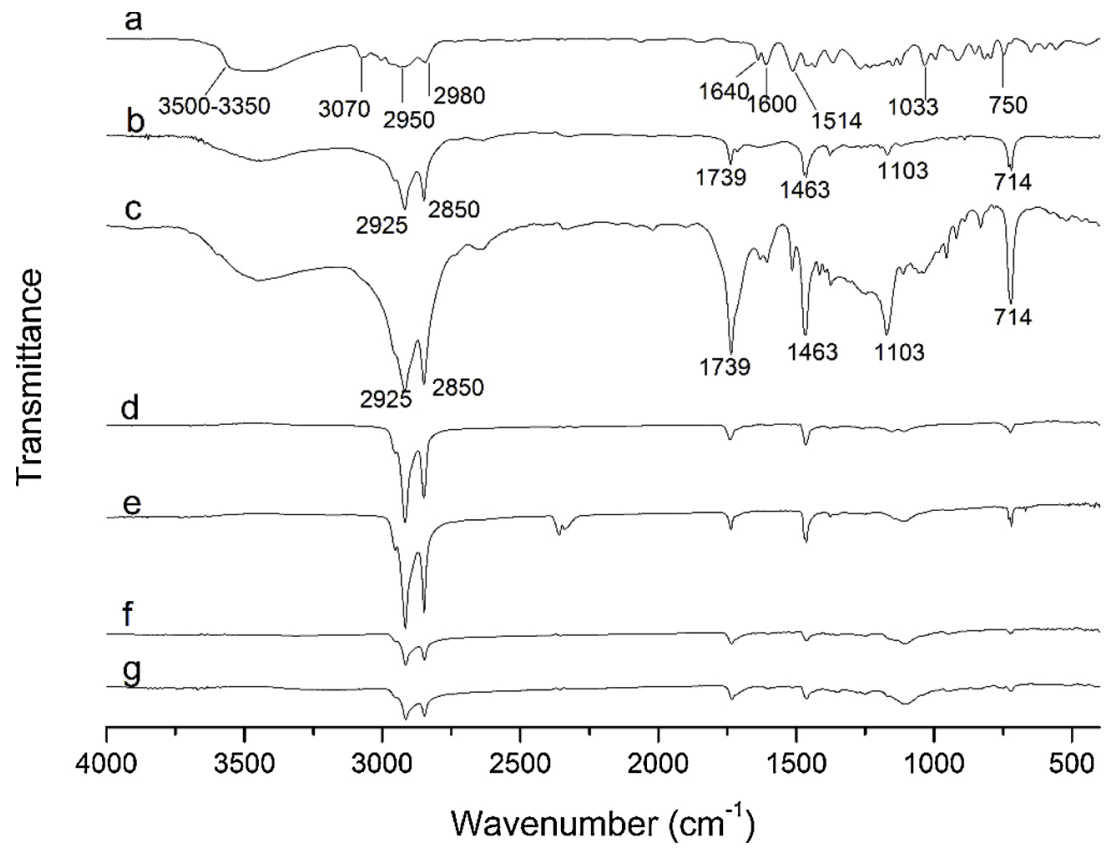

Fig. 2. FT-IR spectra of (a) pure clove oil, (b) beeswax (BW), (c) carnauba wax (CW), (d) BW4, (e) BW7, (f) CW4, and (g) CW6.

was found in spectra $\mathbf{f}$ and $\mathbf{g}$ (NLC formulations containing clove oil), indicating the overlapping of the clove oil spectra with the waxes spectra probably due to the low amount of the oil in the formulations as already reported by other authors $[44,45]$.

Fig. 3 shows second heating and first cooling runs of bulk waxes (BW, CW), NLC formulations without (BW4/CW4) and with the highest amount of clove oil (BW7/CW6) analyzed by DSC.

The heat flow curve for bulk BW showed an endothermic melting peak with homogeneous melting and melting temperature $\left(\mathrm{T}_{\mathrm{m}}\right) 57^{\circ} \mathrm{C}$ (Fig.3a). The NLC BW4 had a pre-melting (left shoulder) followed by complete melting, which is associated to the presence of a high amount of crodamol $(10 \mathrm{wt} \%)$ in the formulation creating a less crystalline environment and, consequently, melting at a lower temperature while a more ordered structure melts at a higher temperature. The cooling curves (Fig.3b) showed that the presence of crodamol in NLC BW4 assisted the polymorphic transition of the lipid from $\beta$-modification to $\alpha$-modification [46], most dense packing and disordered aliphatic chain conformation, respectively [46-49], confirming the presence of a less ordered structure. On the other hand, formulation NLC BW7 (reduced amount of crodamol (1 wt\%) and high amount of clove oil $9 \mathrm{wt} \%$ ) showed single melting and cooling peaks similar to those found for the bulk wax, revealing the absence of polymorphic transitions. The less ordered crystal lattice is favorable for entrapping molecules and the increase in $\Delta \mathrm{H}$ and decrease in $\mathrm{T}_{\text {onset }}, \mathrm{T}_{\mathrm{m}}, \mathrm{CI}$, and $\Delta \mathrm{T}_{1 / 2}$ (Table 2) for BW NLC formulations compared to the bulk wax indicates that both nanoparticulate formulations possess a portion of less ordered structures, but only BW4 with $10 \mathrm{wt} \%$ of crodamol presented $\alpha \rightarrow \beta$ polymorphic transition.

Fig. 3a also shows the heat flow curve for bulk CW with endothermic and homogeneous melting peak and melting temperature $\left(\mathrm{T}_{\mathrm{m}}\right)$ of $83^{\circ} \mathrm{C}$ while the CW NLC formulations showed a pre-melting at $58^{\circ} \mathrm{C}$ followed by the complete melting, consequently, reducing the $\mathrm{T}_{\text {onset }}$ and an increasing $\Delta \mathrm{T}_{1 / 2}$ of the NLC CW in relation to the bulk wax. The cooling curves presented in Fig.3b show the polymorphism transition from $\beta$ modification to $\alpha$-modification in bulk CW and CW NLC. The result suggests that bulk CW possesses a polymorphic nature and the presence of a shoulder in melting peaks of the CW NLC may be related to the lipid intermediates ( $\beta$ '-modifications) formed during the $\beta \rightarrow \alpha$-polymorphic transition $[38,44,49]$. In addition, some authors associated these $\beta$ 'fractions to the interaction between the lipid and the emulsifier
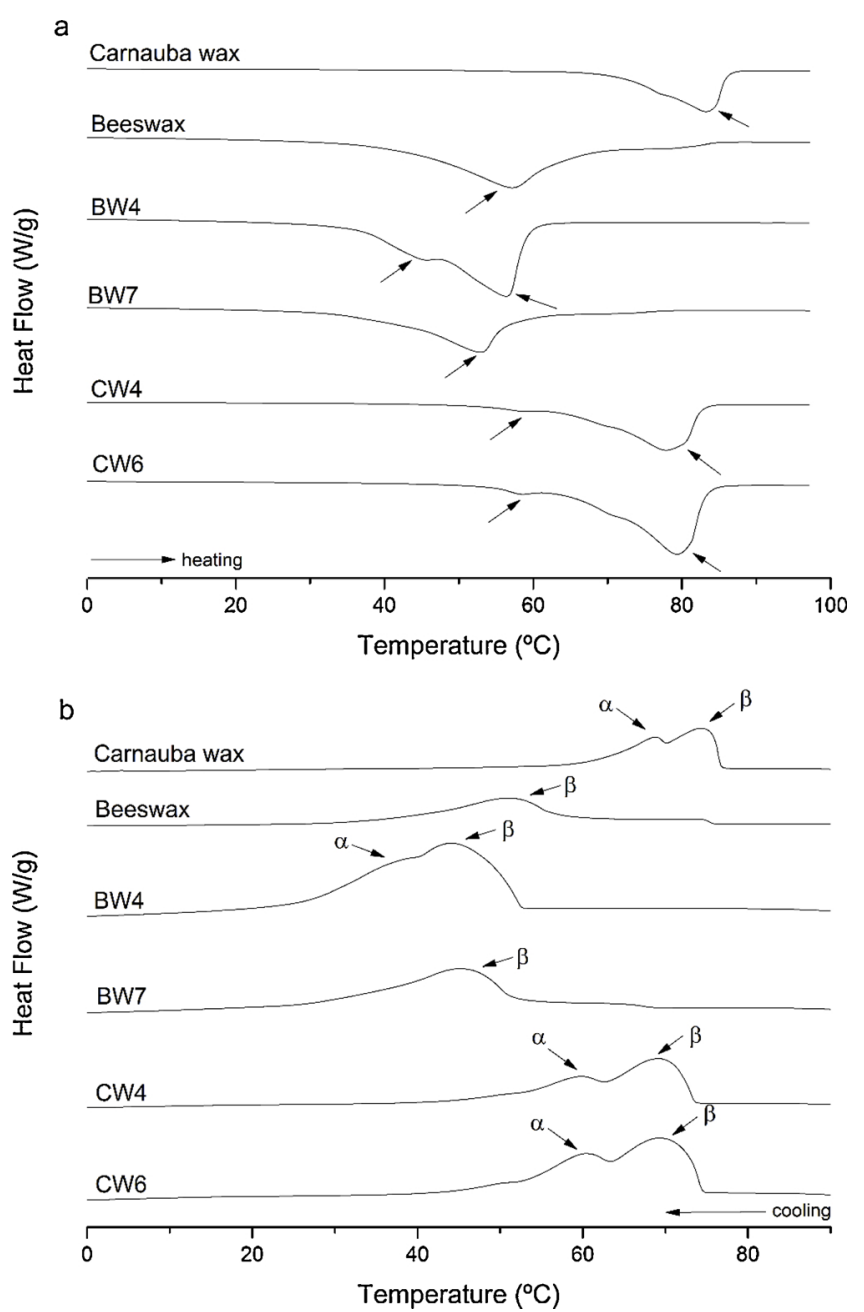

Fig. 3. DSC heating (a) and cooling (b) enthalpies of carnauba wax (CW), beeswax (BW), and formulations BW4, BW7, CW4 and CW6. 
Table 2

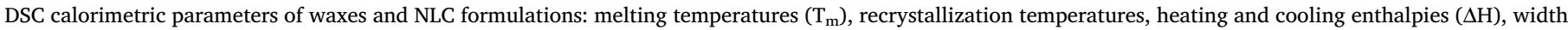
at half height $\left(\Delta \mathrm{T}_{1 / 2}\right)$ and onset temperatures $\left(\mathrm{T}_{\text {onset }}\right)$.

\begin{tabular}{|c|c|c|c|c|c|c|}
\hline \multicolumn{7}{|c|}{ Melting } \\
\hline Parameter & Carnauba wax & Beeswax & BW4 & BW7 & CW4 & CW6 \\
\hline $\mathrm{T}_{\text {onset }}\left({ }^{\circ} \mathrm{C}\right)$ & 72.7 & 51.4 & 36.8 & 48.2 & 55.93 & 56.9 \\
\hline $\mathrm{T}_{\mathrm{m}}\left({ }^{\circ} \mathrm{C}\right)$ & 83.3 & 57.6 & 56.4 & 52.9 & 77.9 & 79.2 \\
\hline$\Delta \mathrm{H}(\mathrm{J} / \mathrm{g})$ & 186.0 & 149.3 & 142.1 & 135.5 & 134.1 & 133.3 \\
\hline CI (\%) & 100.0 & 100.0 & 95.1 & 90.7 & 72.1 & 71.7 \\
\hline$\Delta \mathrm{T}_{1 / 2}\left({ }^{\circ} \mathrm{C}\right)$ & 8.9 & 13.6 & 12.8 & 9.9 & 10.7 & 9.4 \\
\hline \multicolumn{7}{|c|}{ Recrystallization } \\
\hline Parameter & Carnauba wax & Beeswax & BW4 & BW7 & CW4 & CW6 \\
\hline $\mathrm{T}_{\alpha}\left({ }^{\circ} \mathrm{C}\right)$ & 68.7 & - & 38.3 & - & 59.0 & 60.1 \\
\hline $\mathrm{T}_{\beta}\left({ }^{\circ} \mathrm{C}\right)$ & 74.4 & 51.0 & 44.2 & 45.2 & 69.2 & 69.4 \\
\hline$\Delta \mathrm{H}(\mathrm{J} / \mathrm{g})$ & -197.0 & -144.9 & -149.5 & -124.3 & -135.9 & -132.7 \\
\hline
\end{tabular}

$[28,44]$. Other study observed an increase in the left shoulder of the DSC melting curves as the amount of carnauba wax was increased in the formulation and related this thermal behavior directly with the SLN production process and reduction of the particle size [44]. The difference in crystallization and melting temperatures, enthalpies, $\mathrm{T}_{\text {onset }}$, and the sharp decrease in CI between the nanoparticulate and bulk CW samples indicates that the polymorphism of the crystals formed in the NLC are less organized than in the pure wax. The decrease in crystallinity is favorable for compounds entrapment since lattice defects of the lipid structure could offer room to accommodate the drugs, while highly crystalline lipids would lead to drug expulsion [28].

The NLC formulations containing crodamol as liquid lipid showed a semi-crystalline or less ordered structure than the bulk waxes. Similar behavior was reported by other authors $[45,50]$ that used binary lipid combinations to entrap bioactive compounds, and the presence of a liquid lipid in the formulation decreased the crystallinity of the dispersed phase, and consequently, improved the drug encapsulation efficiency. In other words, the use of a liquid lipid increases the number of imperfections and leads to increased drug loading capacity and retention, which composes the first model of NLC called imperfect type NLC [39]. These results indicate that all $\mathrm{BW}$ and $\mathrm{CW}$ formulations containing a fraction of crodamol could be used as a potential system for clove oil delivery. Based on this, the samples containing the highest amount of clove oil were selected for the in vitro $\mathrm{AChE}$ and $\mathrm{BChE}$ inhibition assays.

\subsection{Acetylcholinesterase (AChE) and butyrylcholinesterase (BChE) inhibitory activity}

Drosophila melanogaster homogenate was employed to determine the in vitro inhibitory activity of $\mathrm{AChE}$ and $\mathrm{BChE}$ after the incubation with different concentrations of free and encapsulated clove oil, the activity inhibition (\%) and $\mathrm{IC}_{50}(\mathrm{mM})$ are shown in Fig.4.

Drosophila melanogaster is the closest invertebrate model organism to human based on the gene sequence similarity, and the high sensitivity to toxic substances favors its use as a bioindicator to evaluate the biological action of pharmacological agents [51,52]. The free clove oil dissolved in methanol showed similar efficacy in the inhibition in both cholinergic enzyme (AChE and BChE), and concentrations equal or above $10 \mathrm{mM}$ were able to inhibit completely the enzymes. In this way, the $\mathrm{IC}_{50}$ of free clove oil for AChE inhibition ( $3.5 \mathrm{mM}$ ) was similar to the value found in a previous work [7] that utilized electric eel as the enzyme source (Electrophorus AChE type VI-S). Authors investigated the AChE inhibitory effect of many essential oil components, indicating that the eugenol present in the clove oil plays the same role in the oil activity. Results suggest that the free clove oil had similar activity against both AChE and BChE.

With the encapsulation of clove oil in CW and BW NLC it was possible to decrease the $\mathrm{IC}_{50}$ values to less than $50 \%$ when compared to the free clove oil at the same concentrations. This result indicates that the incorporation of the essential oil in the lipid particles favored the water affinity of the oil since no solvent (such as methanol) was used. A similar result was found in other work that evaluated beta-carotene nanodispersed in water and demonstrated a decrease in the
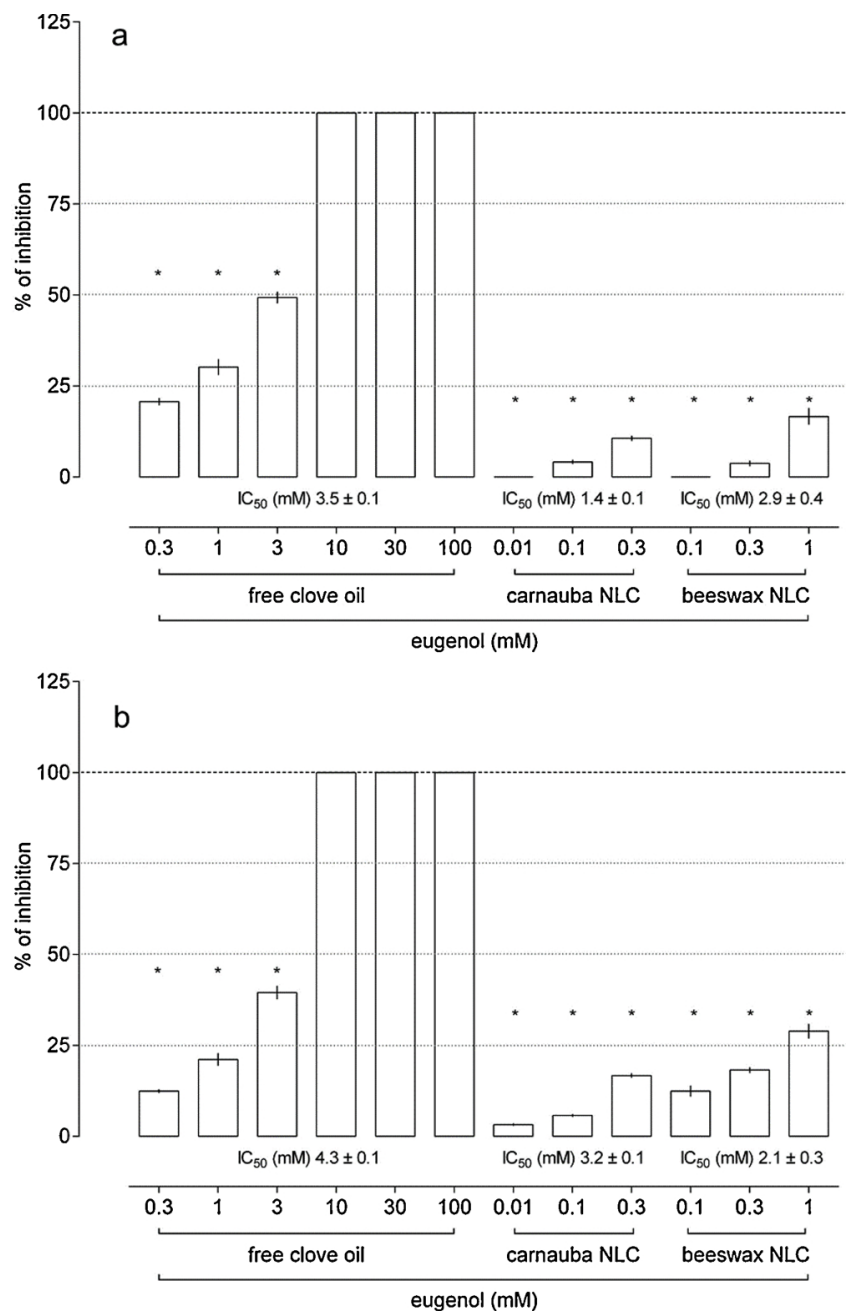

Fig. 4. AChE (a) and BChE (b) inhibitory activity (\%) and $\mathrm{IC}_{50}(\mathrm{mM})$ of the free clove essential oil, clove oil loaded into NLC of carnauba wax (CW6) and beeswax (BW7). Values are mean \pm SEM ( $n=4$ per group). Significance determined by one-way analyses of variance (ANOVA) followed by Tukey's test. ${ }^{*} \mathrm{p}<0.05$ in comparison with the control (100\% of inhibition). 
nanoparticle average diameter increased the beta-carotene dispersibility in water and favored the AChE inhibition [31].

\section{Conclusion}

Clove essential oil was successfully incorporated in natural nanostructured lipid carriers using beeswax or carnauba wax as matrix materials. The presence of a liquid lipid (medium chain triglycerides, crodamol) in the formulation led to the decrease in the average particles size but the sizes distribution remained monodisperse. The solid lipid nanoparticles containing crodamol in formulation presented satisfactory aqueous colloidal stability after 30 days of storage. The particles characterization showed typical nanostructured lipid carrier properties as solid morphology, semi-crystalline environment, and polymorphic transition events. The free clove oil and the solid lipid dispersion containing encapsulated clove oil showed efficient in vitro acetylcholinesterase (AChE) and butyrylcholinesterase (BChE) inhibition in Drosophila melanogaster tissue. In addition, nanostructured lipid formulations showed high inhibition with an $\mathrm{IC}_{50}$ lower than the free clove oil. The free oil was tested in the presence of a good solvent (methanol) while the nanoparticles were evaluated in water only, meaning that the oil bioactivity was potentialized in aqueous medium which is important in a commercial point of view in food and cosmetic applications.

\section{Declaration of Competing Interest}

None.

\section{Acknowledgements}

Authors thank the financial support from CAPES (Coordenação de Aperfeiçoamento de Pessoal de Nível Superior) and CNPq (Conselho Nacional de Desenvolvimento Científico e Tecnológico), and also Laboratório Central de Microscopia Eletrônica of Universidade Federal de Santa Catarina (LCME/UFSC) for TEM analyses.

\section{References}

[1] Y. Konishi, S. Kobayashi, Transepithelial transport of chlorogenic acid, caffeic acid, and their colonic metabolites in intestinal Caco-2 cell monolayers, J. Agric. Food Chem. 52 (2004) 2518-2526, https://doi.org/10.1021/jf035407c.

[2] Z. Kyselova, Toxicological aspects of the use of phenolic compounds in disease prevention, Interdiscip. Toxicol. 4 (2011) 173-183, https://doi.org/10.2478/ v10102-011-0027-5.

[3] F. Topal, I. Gulcin, A. Dastan, M. Guney, Novel eugenol derivatives: potent acetylcholinesterase and carbonic anhydrase inhibitors, Int. J. Biol. Macromol. 94 (2017) 845-851, https://doi.org/10.1016/j.ijbiomac.2016.10.096.

[4] Y. Panahi, A. Akhavan, A. Sahebkar, S.M. Hosseini, M. Taghizadeh, H. Akbari, M.R. Sharif, S. Imani, Investigation of the effectiveness of Syzygium aromaticum, Lavandula angustifolia and Geranium robertianum essential oils in the treatment of acute external otitis: a comparative trial with ciprofloxacin, Journal of Microbiology, Immunology, Infection 47 (2014) 211-216, https://doi.org/10. 1016/j.jmii.2012.10.002.

[5] M.S.A. Khan, I. Ahmad, Biofilm inhibition by Cymbopogon citratus and Syzygium aromaticum essential oils in the strains of Candida albicans, J. Ethnopharmacol. 140 (2012) 416-423, https://doi.org/10.1016/j.jep.2012.01.045.

[6] İ. Gülçin, M. Elmastaş, H.Y. Aboul-Enein, Antioxidant activity of clove oil - a powerful antioxidant source, Arab. J. Chem. 5 (2012) 489-499, https://doi.org/10. 1016/j.arabjc.2010.09.016.

[7] S. Dohi, M. Terasaki, M. Makino, Acetylcholinesterase inhibitory activity and chemical composition of commercial essential oils, J. Agric. Food Chem. 57 (2009) 4313-4318, https://doi.org/10.1021/jf804013j.

[8] S.N. Prasad, Muralidhara, Evidence of acrylamide induced oxidative stress and neurotoxicity in Drosophila melanogaster - Its amelioration with spice active enrichment: Relevance to neuropathy, NeuroToxicology 33 (2012) 1254-1264, https://doi.org/10.1016/j.neuro.2012.07.006.

[9] E.T. Arung, E. Matsubara, I.W. Kusuma, E. Sukaton, K. Shimizu, R. Kondo, Inhibitory components from the buds of clove (Syzygium aromaticum) on melanin formation in B16 melanoma cells, Fitoterapia 82 (2011) 198-202, https://doi.org/ 10.1016/j.fitote.2010.09.008.

[10] M.M. Özcan, D. Arslan, Antioxidant effect of essential oils of rosemary, clove and cinnamon on hazelnut and poppy oils, Food Chem. 129 (2011) 171-174, https:// doi.org/10.1016/j.foodchem.2011.01.055.

[11] P. Goñi, P. López, C. Sánchez, R. Gómez-Lus, R. Becerril, C. Nerín, Antimicrobial activity in the vapour phase of a combination of cinnamon and clove essential oils, Food Chem. 116 (2009) 982-989, https://doi.org/10.1016/j.foodchem.2009.03. 058.

[12] K.P. Devi, S.A. Nisha, R. Sakthivel, S.K. Pandian, Eugenol (an essential oil of clove) acts as an antibacterial agent against Salmonella typhi by disrupting the cellular membrane, J. Ethnopharmacol. 130 (2010) 107-115, https://doi.org/10.1016/j. jep.2010.04.025.

[13] K. Bentayeb, C. Rubio, C. Nerín, Study of the antioxidant mechanisms of Trolox and eugenol with 2,2'-azobis(2-amidinepropane)dihydrochloride using ultra-high performance liquid chromatography coupled with tandem mass spectrometry, Analyst 137 (2012) 459-470, https://doi.org/10.1039/C1AN15505A.

[14] K. Chaieb, H. Hajlaoui, T. Zmantar, A. Ben Kahla-Nakbi, M. Rouabhia, K. Mahdouani, A. Bakhrouf, The chemical composition and BiologicalActivity of clove essential oil, Eugeniacaryophyllata (Syzigium aromaticum L.Myrtaceae): a short review, Phytother. Res. 21 (2007) 501-506, https://doi.org/10.1002/ptr.

[15] W. Brand-Williams, M.E. Cuvelier, C. Berset, Use of a free radical method to evaluate antioxidant activity, Lwt - Food Sci. Technol. 28 (1995) 25-30, https://doi. org/10.1016/S0023-6438(95)80008-5.

[16] A.C. Meneses, C. Sayer, B.M.S. Puton, R.L. Cansian, P.H.H. Araújo, D. Oliveira, Production of clove oil nanoemulsion with rapid and enhanced antimicrobial activity against gram-positive and gram-negative bacteria, J. Food Process Eng. (2019) 1-9, https://doi.org/10.1111/jfpe.13209.

[17] A.C. De Meneses, P. Christina, T.O. Machado, C. Sayer, D. De Oliveira, P.H.H. Araujo, Poly (thioether-ester) nanoparticles entrapping clove oil for antioxidant activity improvement, J. Polym. Res. 24 (2017).

[18] H. Soreq, S. Seidman, Acetylcholinesterase - new roles for an old actor, Nat. Rev. Neurosci. 2 (2001) 284-302, https://doi.org/10.1038/35067589.

[19] Z. Fang, B. Bhandari, Encapsulation of polyphenols - A review, Trends Food Sci. Technol. 21 (2010) 510-523, https://doi.org/10.1016/j.tifs.2010.08.003.

[20] D.A. Oliveira, M. Angonese, S.R.S. Ferreira, C.L. Gomes, Nanoencapsulation of passion fruit by-products extracts for enhanced antimicrobial activity, Food Bioprod. Process. 104 (2017) 137-146, https://doi.org/10.1016/j.fbp.2017.05. 009.

[21] H.M. Nguyen, I.C. Hwang, J.W. Park, H.J. Park, Photoprotection for deltamethrin using chitosan-coated beeswax solid lipid nanoparticles, Pest Manag. Sci. 68 (2012) 1062-1068, https://doi.org/10.1002/ps.3268.

[22] A. Mousavi, S. Mohammad, B. Hashemi, S. Limbo, Food and Bioproducts Processing Antimicrobial agents and packaging systems in antimicrobial active food packaging: an overview of approaches and interactions, Food Bioprod. Process. 111 (2018) 1-19, https://doi.org/10.1016/j.fbp.2018.05.001.

[23] H.R. Kelidaria, R. Babaeib, M. Nabilic, T. Shokohid, M. Saeedif, S. Gholamid, M. Moazenid, A. Nokhodchig, Improved delivery of voriconazole to Aspergillus fumigatus through solid lipid nanoparticles as an e ff ective carrier, Colloids Surf. A Physicochem. Eng. Asp. 558 (2018) 338-342, https://doi.org/10.1016/j.colsurfa. 2018.08.082.

[24] E.B. Souto, S. Wissing, C.M. Barbosa, R.H. Müller, Development of a controlled release formulation based on SLN and NLC for topical clotrimazole delivery, Int. J. Pharm. 278 (2004) 71-77, https://doi.org/10.1016/j.ijpharm.2004.02.032.

[25] R.H. Müller, M. Radtke, S.A. Wissing, Solid lipid nanoparticles (SLN) and nanostructured lipid carriers (NLC) in cosmetic and dermatological preparations, Adv. Drug Deliv. Rev. 1 (2002) 131-155.

[26] M. Ghodrati, M.R. Farahpour, H. Hamishehkar, Encapsulation of Peppermint essential oil in nanostructured lipid carriers: in-vitro antibacterial activity and accelerative effect on infected wound healing, Colloids Surf. A Physicochem. Eng. Asp. 564 (2019) 161-169, https://doi.org/10.1016/j.colsurfa.2018.12.043.

[27] K. Khezri, M.R. Farahpour, S. Mounesi Rad, Accelerated infected wound healing by topical application of encapsulated Rosemary essential oil into nanostructured lipid carriers, Artificial Cells, Nanomed. Biotechnol. 47 (2019) 980-988, https://doi.org/ 10.1080/21691401.2019.1582539.

[28] S. Kheradmandnia, E. Vasheghani-Farahani, M. Nosrati, F. Atyabi, Preparation and characterization of ketoprofen-loaded solid lipid nanoparticles made from beeswax and carnauba wax, Nanomed. Nanotechnol. Biol. Med. 6 (2010) 753-759, https:// doi.org/10.1016/j.nano.2010.06.003.

[29] P. Severino, S.C. Pinho, E.B. Souto, M.H. a Santana, Polymorphism, crystallinity and hydrophilic-lipophilic balance of stearic acid and stearic acid-capric/caprylic triglyceride matrices for production of stable nanoparticles, Colloids Surf. B Biointerfaces 86 (2011) 125-130, https://doi.org/10.1016/j.colsurfb.2011.03.029.

[30] U.B. Pandey, C.D. Nichols, Human disease models in Drosophila melanogaster and the role of the fly in therapeutic drug discovery, Pharmacol. Rev. 63 (2011) 411-436, https://doi.org/10.1124/pr.110.003293.411.

[31] F. Rocha, L. Yumi Sugahara, F.V. Leimann, S.M. De Oliveira, E. Da Silva Brum, R.C. Calhelha, M.F. Barreiro, I.C.F.R. Ferreira, R. Porto Ineu, O.H. Gonçalves, Nanodispersions of beta-carotene: effects on antioxidant enzymes and cytotoxic properties, Food Funct. 9 (2018) 3698-3706, https://doi.org/10.1039/c8fo00804c.

[32] F. Tamjidi, M. Shahedi, J. Varshosaz, A. Nasirpour, Nanostructured lipid carriers (NLC): a potential delivery system for bioactive food molecules, Innov. Food Sci. Emerg. Technol. 19 (2013) 29-43, https://doi.org/10.1016/j.ifset.2013.03.002.

[33] M. Zheng, M. Falkeborg, Y. Zheng, T. Yang, X. Xu, Formulation and characterization of nanostructured lipid carriers containing a mixed lipids core, Colloids Surf. A Physicochem. Eng. Asp. 430 (2013) 76-84, https://doi.org/10.1016/j.colsurfa. 2013.03.070.

[34] L. Becker Peres, L. Becker Peres, P.H.H. de Araújo, C. Sayer, Solid lipid nanoparticles for encapsulation of hydrophilic drugs by an organic solvent free double emulsion technique, Colloids Surf. B Biointerfaces 140 (2016) 317-323, https://doi. org/10.1016/j.colsurfb.2015.12.033.

[35] A.C. Meneses, P.C.M. dos Santos, T.O. Machado, C. Sayer, D. de Oliveira, 
P.H. Hermes de Araújo, Poly(thioether-ester) nanoparticles entrapping clove oil for antioxidant activity improvement, J. Polym. Res. 24 (2017), https://doi.org/10. 1007/s10965-017-1353-x.

[36] G.L. Ellman, K.D. Courtney, V. Andres, R.M. Featherstone, A new and rapid colorimetric determination of acetylcholinesterase activity, Biochem. Pharmacol. 7 (1961) 88-95, https://doi.org/10.1016/0006-2952(61)90145-9.

[37] P.S. Hammond, J.S. Forster, A microassay-based procedure for measuring low levels of toxic organophosphorus compounds through acetylcholinesterase inhibition, Anal. Biochem. 180 (1989) 380-383, https://doi.org/10.1016/0003-2697(89) 90449-1.

[38] H. Bunjes, K. Westesen, M.H.J. Koch, Crystallization tendency and polymorphic transitions in triglyceride nanoparticles, Int. J. Pharm. 129 (1996) 159-173, https://doi.org/10.1016/0378-5173(95)04286-5.

[39] C. Pardeshi, P. Rajput, V. Belgamwar, A. Tekade, G. Patil, K. Chaudhary, A. Sonje, Solid lipid based nanocarriers: an overview, Acta Pharm. 62 (2012) 433-472, https://doi.org/10.2478/v10007-012-0040-z.

[40] J. Margelos, G. Eliades, C. Verdelis, G. Palaghias, Interaction of calcium hydroxide with zinc oxide-eugenol type sealers: a potential clinical problem, J. Endod. 23 (1997) 43-48, https://doi.org/10.1016/S0099-2399(97)80206-3.

[41] A. Garg, B. Gupta, R. Prakash, S. Singh, Preparation and characterization of hydroxypropyl- $\beta$-cyclodextrin inclusion complex of eugenol: differential pulse voltammetry and (1)H-NMR, Chem. Pharm. Bull. 58 (2010) 1313-1319, https://doi. org /10.1248/cpb.58.1313.

[42] N.M. Ranjha, H. Khan, S. Naseem, Encapsulation and characterization of controlled release flurbiprofen loaded microspheres using beeswax as an encapsulating agent, J. Mater. Sci. Mater. Med. 21 (2010) 1621-1630, https://doi.org/10.1007/s10856010-4034-4.

[43] B. Zimnicka, A. Hacura, An investigation of molecular structure and dynamics of crude beeswax by vibrational spectroscopy, Polish J. Environ. Stud. 15 (2006) 4-6.

[44] A.R. Madureira, D.A. Campos, P. Fonte, S. Nunes, F. Reis, A.M. Gomes, B. Sarmento, M.M. Pintado, Characterization of solid lipid nanoparticles produced with carnauba wax for rosmarinic acid oral delivery, RSC Adv. 5 (2015) 22665-22673, https:// doi.org/10.1039/c4ra15802d.

[45] A. Garg, S. Singh, Enhancement in antifungal activity of eugenol in immunosuppressed rats through lipid nanocarriers, Colloids and Surfaces, B, Biointerfaces 87 (2011) 280-288, https://doi.org/10.1016/j.colsurfb.2011.05.030.

[46] K. Larsson, Classification of glyceride crystal forms, Acta Chem. Scand. 20 (1966) 2255-2260, https://doi.org/10.3891/acta.chem.scand.20-2255.

[47] R.N.A.H. Lewis, D.A. Mannock, R.N. Mcelhaney, Differential scanning calorimetry in the study of lipid phase. Practical considerations, Methods Mol. Biol. 400 (2007) 171-195, https://doi.org/10.1007/978-1-59745-519-0 12.

[48] C. Himawan, V.M. Starov, A.G.F. Stapley, Thermodynamic and kinetic aspects of fat crystallization, Adv. Colloid Interface Sci. 122 (2006) 3-33, https://doi.org/10. 1016/j.cis.2006.06.016

[49] K. Sato, Crystallization behaviour of fats and lipids - a review, Chem. Eng. Sci. 56 (2001) 2255-2265, https://doi.org/10.1016/S0009-2509(00)00458-9.

[50] Y. Soleimanian, S.A.H. Goli, J. Varshosaz, S.M. Sahafi, Formulation and characterization of novel nanostructured lipid carriers made from beeswax, propolis wax and pomegranate seed oil, Food Chem. 244 (2018) 83-92, https://doi.org/10 1016/j.foodchem.2017.10.010.

[51] I.A. Adedara, C.V. Klimaczewski, N.B.V. Barbosa, E.O. Farombi, D.O. Souza J.B.T. Rocha, Influence of diphenyl diselenide on chlorpyrifos-induced toxicity in Drosophila melanogaster, J. Trace Elem. Med. Biol. 32 (2015) 52-59, https://doi. org/10.1016/j.jtemb.2015.05.003.

[52] E. Bier, Drosophila, the golden bug, emerges as a tool for human genetics, Nat. Rev. Genet. 6 (2005) 9-23, https://doi.org/10.1038/nrg1503. 